Neuroepidemiology 2011;37:209

DOI: $10.1159 / 000332206$

\section{Toward a Better Understanding of Temporal Patterns of Aneurysmal Subarachnoid Hemorrhage}

Aaron S. Dumont, Pascal M. Jabbour, L. Fernando Gonzalez, Stavropoula I. Tjoumakaris

Division of Neurovascular and Endovascular Surgery, Department of Neurological Surgery, Thomas Jefferson University, Philadelphia, Pa., USA

Lindgren et al. [1] have examined temporal patterns of aneurysmal subarachnoid hemorrhage $(\mathrm{aSAH})$ in a consecutive series of 1,862 patients presenting to Kuopio University Hospital in Eastern Finland within 72 h of ictus between 1980 and 2007. They demonstrate that onset of aSAH occurred more often on Sundays and Mondays and least often on Saturdays. They attempted to analyze variables that may significantly and independently associate with the Sunday and Monday peaks using logistic regression; however, no variables were identified. Admission to Kuopio University Hospital pursuant to aSAH was most frequent on Monday and least frequent on Thursday and Saturday. Additionally, they found that amongst the 1,655 patients undergoing occlusive therapy for their ruptured aneurysm, the procedure was undertaken most frequently on Monday and least frequently on Saturday and Sunday.

The population throughout the study period was relatively homogeneous and Kuopio University Hospital was the sole provider of care in a defined geographic area in Eastern Finland. The Kuopio Intracranial Aneurysm Database, from which the data from the present study were derived, is carefully maintained (with prospective data entry) and cases were only included if the SAH was due to a confirmed saccular aneurysm (rather than including angiogram-negative SAH and SAH secondary to fusiform or mycotic aneurysms). The variables selected to examine for their predictive value for the temporal patterns observed were carefully chosen and the statistical analysis conducted was thorough.
What could account for the observed temporal pattern of aSAH? Unfortunately this study is unable to identify any factors significantly and independently associated with the temporal pattern observed. Attempting to explain the observed pattern remains purely speculative. The authors do raise the issue of whether or not smoking and drinking habits may be significant associated factors. These variables were not available for analysis as they were not included in the database. It is plausible that binge drinking and concentration of this activity on the weekends in the population study could, at least in part, account for the temporal patterns of aSAH uncovered.

Understanding the reasons underlying the observed temporal patterns seen in aSAH from saccular intracranial aneurysms in this population may shed important light into the biology of this disease. An understanding of this basis may possibly allow modification of behavior or risk factors to reduce the risk of aneurysm rupture and its associated calamity and devastation.

The authors of the present study have provided additional information concerning aSAH and their work provides impetus for future research in an attempt to understand etiological factors explaining temporal patterns in aSAH that hopefully can be harnessed for preventative and/or therapeutic purposes.

\section{Reference}

$\checkmark 1$ Lindgren A, Huttunen T, Saavalainen T, Riihinen A, Kurki MI, Koivisto T, Ronkainen A, Rinne J, Hernesniemi J, Jääskeläinen JE, von und zu Fraunberg M: Increased incidence of aneurysmal subarachnoid hemorrhage on Sundays and Mondays in 1,862 patients from Eastern Finland. Neuroepidemiology 2011;37:203-208.

Aaron S. Dumont, MD

Department of Neurological Surgery, Thomas Jefferson University 909 Walnut Street, 2nd Floor Philadelphia, PA 19107 (USA)

Tel. +1 215503 4221, E-Mail aaron.dumont@jefferson.edu

\begin{tabular}{ll}
\hline KARGER & @ 2011 S. Karger AG, Basel \\
0251-5350/11/0374-0209\$38.00/0 \\
$\begin{array}{l}\text { Fax +41 61306 1234 } \\
\begin{array}{l}\text { E-Mail karger@karger.ch } \\
\text { www.karger.com }\end{array}\end{array}$ & $\begin{array}{l}\text { Accessible online at: } \\
\text { www.karger.com/ned }\end{array}$
\end{tabular}

